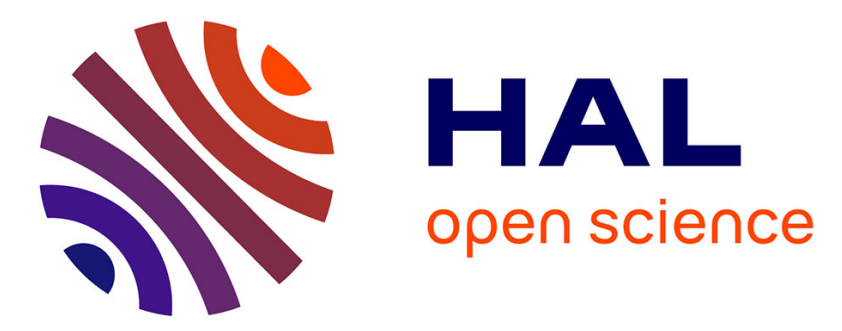

\title{
Supercritical fluid chromatography coupled to mass spectrometry for lipidomics
}

Celine Chollet, Stéphanie Boutet-Mercey, Laurent Laboureur, Carlos Rincon, Marie Méjean, Juliette Jouhet, Francois Fenaille, Benoit A Colsch, David Touboul

\section{To cite this version:}

Celine Chollet, Stéphanie Boutet-Mercey, Laurent Laboureur, Carlos Rincon, Marie Méjean, et al.. Supercritical fluid chromatography coupled to mass spectrometry for lipidomics. Journal of Mass Spectrometry, 2019, 54 (10), pp.791-801. 10.1002/jms.4445 . hal-02374883

\section{HAL Id: hal-02374883 \\ https://hal.science/hal-02374883}

Submitted on 27 Oct 2020

HAL is a multi-disciplinary open access archive for the deposit and dissemination of scientific research documents, whether they are published or not. The documents may come from teaching and research institutions in France or abroad, or from public or private research centers.
L'archive ouverte pluridisciplinaire HAL, est destinée au dépôt et à la diffusion de documents scientifiques de niveau recherche, publiés ou non, émanant des établissements d'enseignement et de recherche français ou étrangers, des laboratoires publics ou privés. 


\title{
1 Supercritical fluid chromatography coupled to mass
} 2 spectrometry for lipidomics

3

4 5 6

7

8

Céline Chollet, ${ }^{1,2}$ Stéphanie Boutet-Mercey, ${ }^{1,3}$ Laboureur Laurent, ${ }^{1}$ Carlos Rincon, ${ }^{1}$ Marie Méjean, ${ }^{1}$ Juliette Jouhet, ${ }^{4}$ François Fenaille, ${ }^{2}$ Benoit Colsch, ${ }^{2}$ David Touboul. ${ }^{1{ }^{*}}$

\section{Affiliations :}

${ }^{1}$ Institut de Chimie des Substances Naturelles, CNRS UPR2301, Université Paris-Sud, Université Paris-Saclay, Avenue de la Terrasse, 91190 Gif-sur-Yvette, France.

2 Service de Pharmacologie et Immuno-Analyse (SPI), Laboratoire d'Etude du Métabolisme des Médicaments, CEA, INRA, Université Paris Saclay, MetaboHUB, F-91191 Gif-sur-Yvette, France.

${ }^{3}$ Institut Jean-Pierre Bourgin, INRA, AgroParisTech, CNRS, Université Paris-Saclay, Versailles, France.

${ }^{4}$ Univ. Grenoble Alpes, CNRS, INRA, CEA, IRIG - LPCV, 38000 Grenoble, France

* Corresponding author: David Touboul, david.touboul@cnrs.fr, Tel: +33169823032

\begin{abstract}
Supercritical fluid chromatography (SFC) has experienced a particular revival in recent years thanks to the development of robust and efficient commercial systems. Due to its physicochemical properties, supercritical carbon dioxide $\left(\mathrm{CO}_{2}\right)$ mixed with co-solvents and additives is particularly suitable for SFC to allow the elution of compounds of different polarity, and more particularly complex lipids. Hyphenation with mass spectrometry (MS) is increasingly described in the literature but still requires many further developments in order to be as userfriendly as coupling with liquid chromatography. The basic concepts of SFC and MS hyphenation will be first considered. Then a representative example of method development in lipidomics will be introduced. In conclusion, the challenges and future needs in this field of research will be discussed.
\end{abstract}




\section{Introduction}

Lipids can be defined as a set of hydrophobic biomolecules with extremely varied physicochemical structures and properties that play multiple biological functions in living organisms. They are an important energy source for organisms and accomplish essential functions in cell compartmentalization and signaling. ${ }^{1}$ However, all of their functions are still not fully known and understood. In human health, lipids are scrutinized for the discovery of biomarkers of pathologies. Indeed, alterations or variations in the concentration of lipids are indicative of dysfunctions in the body that may be linked to pathologies, such as cancer, autoimmune diseases, diabetes and inherited metabolic diseases..$^{2,3}$ In the field of renewable energies, the ability of certain algae to accumulate high levels of some particular lipid species can be exploited for the production of biofuels. ${ }^{4}$

Over the last two decades, technical progress in the development of analytical methods, combined with the growing interest in lipids, has led to a broad development of lipidomic studies. ${ }^{5,6}$ The great diversity of lipids in terms of structure and physico-chemical properties as well as a very wide concentration range ( $\mathrm{pg} / \mathrm{g}$ to $\mathrm{mg} / \mathrm{g}$ of dried tissue) make it difficult to simultaneously separate, detect and annotate all lipid signals in complex biological matrices. The most common chromatographic technique used for lipid analysis is high performance liquid chromatography (HPLC) in normal phase (NPLC) or reverse phase (RPLC). In RPLC, lipids are separated by molecular species according to their polarity depending on the polar head, carbon chain lengths, the number of unsaturations and the presence of hydroxylations and methylations. This method leads to the elution of many lipids of different classes in a reduced chromatographic space that can induce significant ion suppression phenomena. In addition, this chromatographic mode is not compatible with the injection of organic solvents such as chloroform or hexane requiring an extra sample preparation step (drying and resuspension in alcohol). In the opposite, NPLC allows separation by lipid class and is compatible with organic solvent for injection. Nevertheless, the analysis is time consuming (about 30 minutes) and require the use of toxic organic eluents. Gas chromatography (GC) remains mainly focused on fatty acid analysis after saponification of complex lipids and methylation of free fatty acids.

The recent improvement of chromatographic technology based on the use of subcritical/supercritical fluids is of increasing interest to lipidomics research groups. ${ }^{7}$ Indeed, supercritical fluid chromatography (SFC) is considered a hybrid of GC and LC, and has many advantages, such as high separation efficiency, low organic solvent consumption and short analysis time, up to 4 times when comparing LC and SFC with the same column parameters 
1 (internal diameter, length and particle size), required for high-throughput screening. ${ }^{8}$ It is

2 particularly well suited for the analysis of low-polarity compounds, such as lipids, because

3 supercritical $\mathrm{CO}_{2}$ is an non-polar solvent, often compared to hexane. ${ }^{9}$ With some adaptations,

4 which will be described hereafter, SFC can be coupled with mass spectrometry (MS)

5 techniques, providing high mass resolution, mass accuracy and tandem MS in particular, to

6 allow efficient separation and annotation of complex lipid mixtures.

7

\section{History and principles of SFC}

9

Nowadays, carbon dioxide $\left(\mathrm{CO}_{2}\right)$ is by far the most widely used supercritical fluid as a mobile phase in SFC. It is the only fluid for which commercial chromatography systems are available today. The discovery of $\mathrm{CO}_{2}$ in the supercritical phase dates back to 1822 by Baron Charles Cagniard de la Tour (1777-1859), who introduced his work to the "Académie des Sciences" in 1823. ${ }^{10}$ Andrews first described this state as "critical" in 1869 when he determined the critical pressure and temperature $\left(31^{\circ} \mathrm{C}\right.$ and 74 bar $)$ of $\mathrm{CO}_{2} \cdot{ }^{11}$

These two values are fully compatible with pumps and columns conventionally used in LC. Supercritical $\mathrm{CO}_{2}$ displays the advantage of not being toxic to humans at low concentrations, of being chemically inert towards most chemical compounds, non-flammable, odourless and inexpensive. It is also UV transparent as low as $190 \mathrm{~nm}$, allowing the hyphenation with UV detectors using high-pressure cells. The only limitation could be its low solvation power, similar to hexane. ${ }^{12}$ Nevertheless, this limitation is mitigated by the miscibility of supercritical $\mathrm{CO}_{2}$ with the majority of organic solvents (alcohols, acetonitrile). It is therefore possible to modify its solvation power by forming binary $\mathrm{CO}_{2}$ /solvent mixtures. The first chromatographic separation using a supercritical fluid as a mobile phase is attributed to Klesper et al. in $1962 .{ }^{13}$ The mobile phase then consisted of a halogenated alkane and the stationary phase of polyethylene glycol.

In its early days, SFC was considered as an extension of gas chromatography (GC). The authors describe it as a chromatography using a dense gas phase allowing the study of thermolabile compounds. The use of a restrictor provided the necessary pressures in the chromatographic columns. Since then, two types of chromatographic columns coexisted until the late 1990s: capillary and packed columns.

The capillary SFC (cSFC) used capillary or "open tubular" columns derived from GC columns. ${ }^{14}$ They consisted of a fused silica capillary with an internal diameter of $50 \mu \mathrm{m}$ and a stationary phase film on the wall. High pressure was maintained using a restrictor at the outlet of the chromatographic column. The instrumentation was similar to that used in GC, notably 
1 for detection using a flame ionization detector (FID). The FID was perfectly suited when using 2 pure $\mathrm{CO}_{2}$ since it does not provide a FID signal. However, FID is incompatible with mobile phases consisting of a binary mixture $\left(\mathrm{CO}_{2}\right.$ /polar modifier) since the polar modifier leads to a high FID signal. Until the early 1990s, cSFC was the most widespread SFC technique. The use of $\mathrm{CO}_{2}$ at low flow rates (a few $\mathrm{mL} / \mathrm{min}$ ) also allowed coupling to mass spectrometry. However, cSFC shows long analysis times and low column efficiencies compared to GC with the same column. ${ }^{15}$ This type of column is now very uncommon in SFC since all commercial systems use packed columns.

The packed-SFC consists of the use of packed columns and reflects the fact that the SFC can also be considered as the extension of liquid chromatography. In 1983, Hewlett-Packard launched the first commercial SFC system. This system is directly based on a commercial HPLC system. The use of packed columns increases the interaction surfaces with the stationary phase and reduces dead volumes. ${ }^{16}$ Due to the low viscosity of supercritical fluids (Table 1), the pressure drops in the system are lower than in LC. It is therefore technically possible to increase the flow rate of the mobile phase without the risk of reaching the instrumental limits. Moreover, considering the high diffusion coefficient value, this increase in flow rate has no impact on the quality of the separations. These properties often lead to flow rates that are 3 times higher in SFC than LC, but at the same time, a lower organic solvent consumption since most of the mobile phase is composed of $\mathrm{CO}_{2}$. As in $\mathrm{LC}$, the mobile phase can be made up of a binary mixture: a co-solvent (or polar modifier) is added to the $\mathrm{CO}_{2}$ in order to modulate the elution strength of the mobile phase. ${ }^{17}$ In practice, the most commonly encountered co-solvent is ethanol since it allows a high modulation of elution strength, is available in analytical grade, is inexpensive and bears a relative low toxicity. Other solvents such as methanol, isopropanol and less frequently acetonitrile are also used. This strategy allows the study of more polar compounds and extends the scope of the SFC, particularly to pharmaceutical compounds. ${ }^{18}$ However, when the compounds studied are polar, the mobile phase composed of a binary mixture no longer reaches satisfactory chromatographic performance. The obtained peaks are then extremely deformed. Figure 1 shows an example from which the addition of ammonium acetate at a concentration of $15 \mathrm{mmol} / \mathrm{L}$ in the co-solvent significantly improved peak shape. The most common additives are acetic and formic acids, ammonium acetate or formate, and water. It should be noticed here that water is considered as an additive and not a co-solvent. Indeed, since water and $\mathrm{CO}_{2}$ are not miscible, only a few percent ( 1 to $5 \%$ ) of water can be added to the co-solvent. ${ }^{19}$ Additives can act in different ways. For example, they can avoid ionization (by modifying the $\mathrm{pH}$ ), interact with active sites of the stationary phase or form ion pairs with charged analytes. ${ }^{20}$ These additives can sometimes significantly modify the stationary phase and thus modify the characteristics of a 
column. When coupling to mass spectrometry, the additive must be carefully chosen not to interfere with the ionization of analytes or pollute the analyzers. Amines (isopropylamine, dimethylamine, triethylamine), quaternary amine salts and trifluoroacetic acid should be thus avoided.

Given the compressibility of the mobile phase, a back pressure regulator (BPR) is required to maintain the mobile phase pressurized through the system. This regulator is an automated valve that imposes pressure at the outlet of the column regardless of the flow rate through it. Although very important when pure $\mathrm{CO}_{2}$ is used as a mobile phase, the value of the back pressure generally shows a weak influence when a binary mobile phase is used. Effects on retention are minimal and those on selectivity are almost non-existent. To maximize the chances of observing effects, it is necessary to make changes with relatively large steps (at least 20 bar).

There is no ideal and universal stationary phase chemistry in SFC. However, the choice of the stationary phase can be based on the work of Lesellier's group. ${ }^{21}$ They propose a classification by studying the retention factors $(k)$ obtained when separating a mixture of 109 molecular compounds under identical chromatographic conditions (except the stationary phase chemistry). This classification is based on column characterization via quantitative structureretention relationships (QSRRs).

The equation to be solved for each column is as follows:

$\log k=c \mathrm{C}+e E+s S+a A+b B+v V+d^{-} D^{-}+d^{+} D^{+}$

Upper-case letters are variables corresponding to each compound. Lower-case letters are the constants to be determined for each column. $\mathrm{C}$ is the intercept term for the model. $\mathrm{E}$ is linked to the refractive index of the analyte, $S$ to the polarity/apolarity of the analyte, $A$ and $B$ to the acid and basic characteristics of the hydrogen bonds, $V$ is the McGowan volume, $\mathrm{D}^{+}$ represents the charges carried by a cation and $D^{-}$those carried by an anion. ${ }^{22}$ Initially the $D$ terms were not included in the original model. ${ }^{23}$ This resulted in poor classification when ionic or zwitterionic species were considered. However, the calculation of these constants causes problems since it requires knowledge of both $\mathrm{pH}$ and $\mathrm{pKa}$ in situ. Indeed, the pKa of an analyte depends on its environment and is not measurable in SFC. Similarly, the $\mathrm{pH}$ of the mobile phase is difficult to measure experimentally. West et al. propose the use of colored indicators and estimate the "apparent aqueous" $\mathrm{pH}$ of the mobile phase $\mathrm{CO}_{2} / \mathrm{MeOH}$ (with or without basic additives) to be between 2 and 8 and close to 1 when using acid additives. ${ }^{24} \mathrm{~A}$ double approximation was therefore agreed by the authors: use a pH value equal to $5^{25}$ and the pKa obtained in aqueous solution. The final results are presented in the form of a spider diagram where each axis corresponds to a constant (Figure 2). Although very 
useful to get an idea of columns with similar or orthogonal selectivities, this classification can show some limitations, especially when using additives or a co-solvent significantly different from an alcohol. ${ }^{26}$ For these reasons, each new project starts with a column screening in our laboratory.

Currently, the range of commercial equipments is quite limited. Indeed, almost all authors in the literature use UPC² system (Waters) or Infinity 1260 SFC system (Agilent Technologies). It should be noted that other manufacturers sell analytical SFC systems (Shimadzu, Pic Solution or Jasco). All these systems use chromatographic columns with geometries similar to liquid chromatography (Figure 3). These systems are based on the knowledge and experience of ultra-high performance liquid chromatography (UHPLC) manufacturers since they operate at pressures comparable to SFC. The commercialization of these reliable and robust systems has enabled SFC to find its place alongside LC and GC in the world of analytical chemistry.

\section{SFC-MS hyphenation}

Mass spectrometry is the most widely used detection system for lipidomics studies. The coupling of SFC with MS is highly valuable because it combines the efficiency and speed of the SFC separation with the contribution of the high sensitivity and specificity of MS detection. Atmospheric pressure sources such as electrospray (ESI), atmospheric pressure photoionization (APPI) and atmospheric pressure chemical ionization (APCl) are well suited for coupling with SFC and allow the analysis of compounds with different polarities. ${ }^{27,28,29,30}$ All mass analyzers can be coupled to the SFC, and the choice will depend on the study issue: low-resolution analyzers, such as the quadrupole, only provide access to the nominal mass of the compound, while high-resolution analyzers, such as Orbitrap or Time-of-Flight (TOF) analyzers, provide access to the accurate mass of the ions. In the case of studies of complex biological environments, the use of high-resolution mass spectrometry (HRMS) is most often necessary for untargeted profiling whereas triple quadrupoles are required for targeted quantitative approaches.

The coupling of atmospheric pressure ionization sources with SFC is significantly more challenging than with LC. Although the properties of the supercritical fluid are favorable for nebulization, its expansion at the outlet of the column results in poor solvation of the solutes. The latter may then precipitate into the transfer capillary to the ionization source. To avoid this problem and facilitate the ionization of the compounds, a solvent, called a "make-up" solvent, is added using an isocratic pump and a "T" or "Y" type fitting. The choice of this solvent 
depends on the nature of the compounds to be analyzed and must be optimized in order to increase the solubility of the components and promote their ionization. For this purpose, it is possible to test any type of solvent and additives, ensuring that they are miscible with the mobile phase and compatible with the ionization source. The addition of a make-up solvent is required for lipid quantifications for better repeatability. Finally, in order to avoid the condensation of $\mathrm{CO}_{2}$ during its expansion, a module called "caloratherm", consisting of a heated sheath whose temperature is regulated to a chosen value, is placed just before the source.

Several types of interfaces were reviewed and compared by Pinkston first in $2005,{ }^{18}$ then by Grand-Guillaume Perrenoud et al. in 2014. ${ }^{31}$ Very recently, Tarafder published a review of the different solutions proposed for coupling SFC to MS (Figure 4), and their effects on dispersion and chromatographic resolution. ${ }^{32}$

Two configurations are currently operated for coupling with a mass spectrometer: either the coupling takes place after the back pressure regulator BPR, and in this case all the chromatographic effluent is injected into the ionization source, or it can be done before the BPR, using a split system. Although the first configuration (Figure 4d) allows to obtain a good sensitivity, BPR generates important dead volumes which induce a consequent loss of chromatographic efficiency. The introduction of the split system makes it possible to minimize dead volumes (Figure 4e-f). Even if only a part of the sample is introduced, the effects of dilution would be compensated by thinner chromatographic peaks. In addition, the possibility of adding make-up solvent after BPR has also been described in the literature.

Few systematic studies have compared the ionization efficiency of ESI, APCI and APPI sources in coupling with SFC. Méjean et al. reported that the APPI source is significantly more sensitive and robust than $\mathrm{ESI}$ and $\mathrm{APCl}$ for the quantification of tocopherols and tocotrienols in edible oils. ${ }^{27}$ To obtain the best ionization conditions, all voltage and gas pressure parameters must be carefully optimized. In this sense, Duval et al. published an extensive study on the influence of different source parameters in APCI for the detection and quantification of lipids in vegetable oils. ${ }^{33,34}$ Since no liquid phase reaches the ion source but rather a disperse phase in $\mathrm{CO}_{2}, \mathrm{APCl}$ and APPI sources often display the best performance in terms of sensitivity and robustness.

\section{Targeted and untargeted lipidomics}


Lipidomic studies can be designed according to two approaches, i.e. targeted or untargeted studies. The first aims to extract, enrich and quantify specific lipids from a complex matrix. The second consists of the least selective extraction and large-scale profiling methods of all molecular species present in the sample. Both approaches are well suited to lipidomics because of the wide dynamic range of concentration and the high structural diversity of lipids in tissues, biological fluids or other samples of interest.

7

Targeted lipidomics methods in SFC-MS have been focused on several classes such as free fatty acids (C18 column, methanol/acetonitrile (50:50, v/v) with $0.1 \%$ formic acid) ${ }^{35}$ or vitamin $\mathrm{E}$ derivatives in vegetable oils $\left(\mathrm{NH}_{2}\right.$ column, pure ethanol), ${ }^{27}$ carotenoids in human plasma (C30 column, pure methanol), eicosanoids in human plasma and cerebrospinal fluid (2picolamine column, $\mathrm{MeOH}$ with $0.1 \%$ formic acid and $10 \mathrm{mM}$ of ammonium acetate) ${ }^{36}$ steroids (2-ethylpyridine column, pure isopropanol), ${ }^{37}$ environmental toxins as acetogenins (2ethylpyridine column, pure ethanol). ${ }^{28}$ These examples perfectly demonstrate the diversity of stationary phase and co-solvent that are described in the literature and which contrast strongly with HPLC studies that lead mainly to the use of C18 columns and water/acetonitrile gradients.

For profiling of complex lipid mixtures, the studies mainly focused on animal and human plasma lipid extracts. It is indeed a good model and a rapid access route to biomedical applications for treatment monitoring or pathology biomarker research. T. Bamba's group has been a pioneer in this field by demonstrating the class separation of a total lipid extract of Madagascar Periwinkle by SFC-ESI-MS. ${ }^{38}$ The authors use a mixture of 14 lipid standards to develop their method. The final chromatographic method requires a cyano column $(250 \mathrm{~mm} x$ $4.6 \mathrm{~mm} \times 5 \mu \mathrm{m}$ ) and employs methanol with $0.1 \%$ ammonium formate as co-solvent. The gradient was programmed over 20 minutes without taking into account rinsing and equilibration times. Several co-elutions were observed, including between phosphatidic acids (PA), phosphotidylethanolamines (PE) and phosphotidylinositols (PI) as well as between phosphatidylserines (PS), phosphatidylcholines (PC) and sphingomyelins (SM). Limits of detection (LODs) were in the range of $60 \mathrm{pmol}(\mathrm{PC})$ to $15,000 \mathrm{pmol}(\mathrm{PI})$ injected. An Inertsil ODS-EP column ( $250 \mathrm{~mm} \times 4.6 \mathrm{~mm} \times 5 \mathrm{~mm}$, GL Sciences) was then chosen in 2011 for the separation of ten polar lipid classes after Trimethylsilyl (TMS) derivatization in 10 minutes. ${ }^{39}$ This method led to symmetrical and thin chromatographic peaks, but the derivatization step remains time consuming. Nevertheless, the sensitivity was greatly improved with LODs in the range of 5 (sphingosine-1-phosphate, S1P) to $300 \mathrm{fmol}(\mathrm{PA})$ injected and the method was successfully tested on sheep plasma. The initial underivatized method was then improved in 2012 by using a PC-HILIC column for the separation of polar lipids (PC, PE, SM) from dried plasma spot analysis ${ }^{40}$ and in 2018 by a diethylamine (DEA) column and a co-solvent 
methanol/water $(95 / 5, \mathrm{v} / \mathrm{v})$ with $0.1 \%$ formic acid for wide profiling of rabbit plasma lipids. ${ }^{41}$ Nineteen lipid classes were detected in less than 20 minutes and 413 species were annotated and semi-quantified according to MS/MS data with limits of quantification (LOQs) from 5 (PC) to $1000 \mathrm{fmol}$ (lysoPA).

M. Holcapek's group also demonstrated the separation of 30 lipid classes from 6 families of lipids (fatty acyles, phospholipids, glycerolipids, sphingolipids, sterols and derivatives, prenols) in less than 6 minutes with a stationary phase BEH silica column $(100 \mathrm{~mm} \times 3 \mathrm{~mm} \times 1.7 \mu \mathrm{m}$, Waters) and a co-solvent methanol-water mixture (99:1, v/v) containing $30 \mathrm{mM}$ of ammonium acetate. ${ }^{42}$ By injecting a lipid extract from pig brain, the authors controlled the separation by class by observing ion chromatograms extracted from several species belonging to the same lipid class.

Tests with a similar stationary phase were conducted in our team for the analysis of microalgae extracts but led to the co-elution of glycolipids of interest (monogalactosyldiacylglycerol (MGDG), digalactosyldiacylglycerol (DGDG), diacylglyceryltrimethylhomoserine (DGTS) and sulfoquinovosyl diacylglycerol (SQDG)) with sphingolipids and phospholipids. This observation led us to start a classic method development as briefly described below.

\section{Method development}

The set-up available in our laboratory is based on a 1260 Infinity Analytical SFC system hyphenated to a 6540 Q-ToF mass spectrometer (Agilent Technologies, Waldbronn, Germany). A make-up solvent is added between the analytical column and the BPR. The chromatographic flow is then directly introduced to the mass spectrometer through a capillary $(500 \times 0.17 \mathrm{~mm})$. As previously described by the group of Bamba, ${ }^{41}$ we chose a Torus-DEA column $(150 \mathrm{~mm} \times 2.1 \mathrm{~mm} \times 1.7 \mu \mathrm{m})$ for the method development. The lipid extract of Nannochloropsis gaditana microalgae was provided by J. Jouhet (CEA Grenoble). It was prepared according to the following protocol: the cells were collected by centrifugation and immediately frozen in liquid nitrogen. The pellets were suspended in $4 \mathrm{~mL}$ of ethanol and boiled for 5 minutes to prevent the degradation by phospholipases. Lipid extraction was then performed by adding $10 \mathrm{~mL}$ of chloroform/methanol mixture $(4: 1, \mathrm{v} / \mathrm{v})$ at room temperature. The solution obtained was shaken for 1 hour at room temperature under argon to avoid any oxidation. After filtration on quartz wool filter, the cells were rinsed with $3 \mathrm{~mL}$ of chloroform/methanol mixture $(2: 1, \mathrm{v} / \mathrm{v})$ and $5 \mathrm{~mL}$ of $1 \% \mathrm{NaCl}$ was added to obtain two phases. The lower phase was sampled and dried under argon. A $1 \mathrm{mg} \cdot \mathrm{mL}^{-1}$ stock solution was prepared in a chloroform/methanol mixture $(2 / 1, v / v)$ by weighting the extract and was diluted twice before injection. 
1 A generic gradient ranging from 1 to $35 \%$ of ethanol was tested in the first approach. This method allows a partial separation of cholesteryl esters with triglycerides, 1,2- and 1,3diglycerides and polar lipids except SQDG. In order to optimize the separation, a 3 min plateau with $15 \%$ co-solvent was implemented at 2.5 min elution time allowing a separation with baseline resolution of the different lipid classes. Finally, the percentage of co-solvent at the end of the gradient was increased to $45 \%$ allowing the elution of SQDGs and PI which are the most polar species in the mixture. This led to a total time of the SFC run of 20 min including equilibration time. In order to optimize the performance of the SFC-ESI-MS coupling, a set-up with or without split was evaluated by comparing the full widths at half height of the major peaks of the main classes and their peak intensities (Figure S1). The split set-up allows significant refinement of peaks without loss of sensitivity or even a gain, except for the DGs. The final method leads to peaks with a full width at half height between 4 and 6 seconds (Figure 5).

Once the separation dimension has been optimized, it is necessary to ensure the detection of as many species as possible, whatever their polarity and ionizability. In order to ensure the transfer of analytes to the ESI source of the mass spectrometer and to facilitate their ionization, a make-up solvent is therefore added. After optimizing the solvent composition, we chose to use $\mathrm{MeOH} / \mathrm{EtOH} 1: 1(\mathrm{v} / \mathrm{v})$ as the solvent make-up mixture. We added various additives, such as ammonium acetate at $20 \mathrm{mM}$, water at $2 \%(\mathrm{v} / \mathrm{v})$ or formic acid at $0.1 \%$ and $0.5 \%(\mathrm{v} / \mathrm{v})$. Six "make-up" solvents were tested at 3 different flow rates $\left(100,200\right.$, and $400 \mu$ L.min $\left.{ }^{-1}\right)$ monitoring the response of one major species per lipid class (Figure S2). For all additives, the compounds that are eluted at the beginning of the gradient are better ionized with a flow rate of $200 \mu \mathrm{L} \cdot \mathrm{min}^{-1}$, while the compounds that are most retained are better detected with a lower flow rate of $100 \mu \mathrm{L} \cdot \mathrm{min}^{-1}$. In addition, the sensitivity is increased for all lipid classes in positive and negative ionization mode when $20 \mathrm{mM}$ of ammonium acetate are added in the make-up solvent. In that case, ammonium adducts in positive ion mode and acetate adducts in the negative ion mode were mainly detected. Such ionization process led to a better sensitivity for $\mathrm{PC}$ in the negative ion mode even if the molecule bears a permanent positive charge on a quaternary ammonium group. Thus the make-up pump will deliver a mixture of $\mathrm{MeOH} / \mathrm{EtOH}$ $1: 1(\mathrm{v} / \mathrm{v})+20 \mathrm{mM}$ ammonium acetate at $200 \mu \mathrm{L}$. $\mathrm{min}^{-1}$ from 0 to 6 minutes, then $100 \mu \mathrm{L} \cdot \mathrm{min}^{-1}$ from 7 to 19 minutes. It should be noted that the change of the make-up flow during the analysis was not described in the literature and should be compared to the LC-CAD set-up that allows the same solvent composition arriving at the detector to be maintained throughout the analysis.

Finally, the gas temperatures, the voltages applied to the ESI probe and at the fragmentor were optimized in positive and negative ionization mode leading to sensitivities in the order of 
$110 \mathrm{pg} / \mathrm{mg}$ of extracts. A mass spectrum extracted between $0.87 \mathrm{~min}$ and $1.79 \mathrm{~min}$ is used to annotate up to 34 triglycerides (Figure 6). It should be noted that within the same lipid class, a partial separation of molecular species is demonstrated according to the number of carbons of the fatty chains (Figure S3).

\section{Future Developments}

7

Although the coupling between supercritical fluid chromatography and mass spectrometry has been demonstrated for more than ten years, this technology still faces many challenges in becoming a universal technique like LC-MS. The choice of a large number of stationary phases can be considered as a particularly attractive aspect for carrying out analytical studies but often discourages new users and can be judged as a waste of time and efficiency in an analytical platform context requiring simple and robust methods. Thus, the stationary 2ethylpyridine phase is often viewed as a versatile phase in the literature but is not widely used in the context of lipidomics as previously described. The arrival of new stationary phases based on highly basic material nevertheless opens the way to the gradual removal of additives, i.e. ammonium salts in particular, which require fairly long equilibration and rinsing times for the columns. In the context of lipidomics, it should be noted that the use of chiral stationary phases is rarely described in the literature and deserves particular attention, especially for the separation of arachidonic acid derivatives (leukotriens, prostaglandins, thromboxanes, etc.). The SFC-MS interface itself still requires further improvements to eliminate peak expansion or molecule condensation phenomena leading to significant sensitivity losses. Nowadays, SFC-MS is still considered less sensitive than LC-MS by one to two orders of magnitude. Nowadays, APCI and APPI sources, although less popular than ESI sources, appear to be the most suitable for analyzing effluent arriving at the source in the form of a pneumatic spray by expanding $\mathrm{CO}_{2}$ at atmospheric pressure. It is recommended to set up designed experiments to determine the optimal ionization parameters during method development, especially for targeted approaches where trace quantification may be required. As an interlaboratory study was undertaken in SFC-UV, ${ }^{43}$ it would be extremely attractive to carry out the same work with different SFC-MS platforms.

Concerning lipidomics studies in SFC-MS, the pioneering works of T. Bamba and M. Holcapeck have paved the way for applications in biology, cosmetics or biofuels. The cost of instrumentation and the time required to optimize methods remain a barrier to the dissemination of these methods, which have the advantage of being efficient in terms of separation, fast with analysis times of 20 minutes compared to more than 45 minutes in NPLC for lipid separation by class, and sensitive. Conditions for high-throughput screening are now met and SFC-MS studies should be expanded in this direction. In addition, the adaptation of 
1 modern methods for MS/MS annotation of lipids by post-column cationization, ${ }^{28}$ method for

2 labelling double bonds via the Paternò-Büchi reaction ${ }^{44}$ or the use of molecular networks for 3 data classification ${ }^{45}$ have yet to be developed in the near future.

4

5

6 Acknowledgements

7 This work was supported by the Agence Nationale de la Recherche (Grant ANR-16-CE29-

8 0002-01 CAP-SFC-MS).

9

10 
1 Table 1: Orders of magnitude of physical properties of solvents in different states

Type of fluid

$\begin{array}{cccc}\text { Property } & \text { Gas } & \text { SCF } & \text { Liquid } \\ \text { Density, } \mathrm{r}\left(\mathrm{g} . \mathrm{cm}^{-3}\right) & 10^{-3} & 0.3 & 1 \\ \text { Diffusivity, D }\left(\mathrm{cm}^{2} . \mathrm{s}^{-1}\right) & 10^{-1} & 10^{-3} & 5 \times 10^{-6} \\ \text { Viscosity, h }\left(\mathrm{g} . \mathrm{s} . \mathrm{cm}^{-1}\right) & 10^{-4} & 10^{-4} & 10^{-2} \\ & & & \end{array}$


1 Figure 1: Effect of the addition of ammonium acetate $\left(15 \mathrm{mmol} . \mathrm{L}^{-1}\right)$ on the peak shape of polar 2 compounds. Mix of 3 isomers of methylcytidines. Column Waters Acquity UPC ${ }^{2}$ Torus 2-PIC $3(150 \mathrm{~mm} \times 2.1 \mathrm{~mm} \times 1.7 \mu \mathrm{m}), 150 \mathrm{bar}, 30^{\circ} \mathrm{C}$; Gradient 5 to $20 \%$ of co-solvent $(\mathrm{MeOH})$ in 25 $4 \mathrm{~min}$; Flow rate $1.5 \mathrm{~mL} \cdot \mathrm{min}^{-1}$.

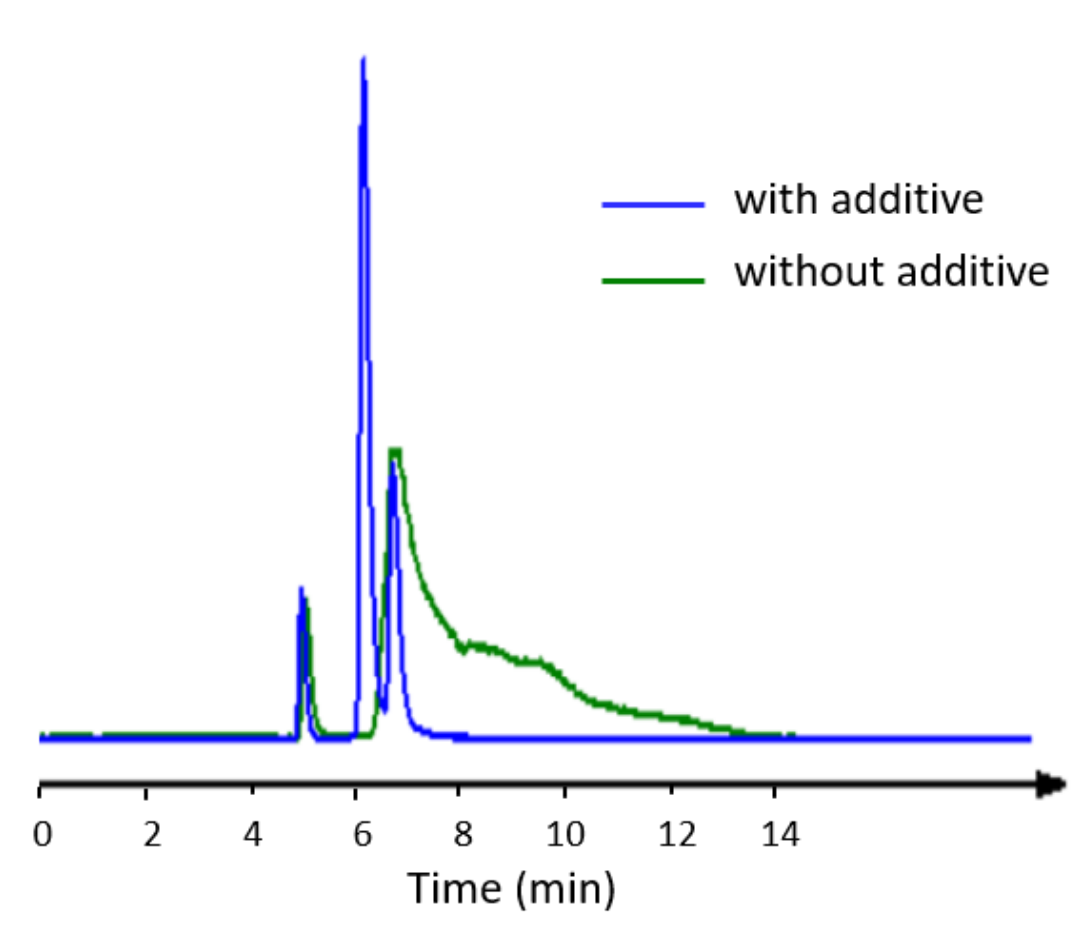


1 Figure 2: Spider diagram proposed by West et al. ${ }^{23}$ representing a column classification based 2 on quantitative structure-retention relationships (QSRRs). Testing conditions: $\mathrm{CO}_{2}-\mathrm{MeOH}$ $390: 10(\mathrm{v} / \mathrm{v}), 25^{\circ} \mathrm{C}, 150$ bar, 1 or $3 \mathrm{~mL} \cdot \mathrm{min}^{-1}$ depending on column dimension. Retention data 4 was measured for 85 neutral species with 31 columns.

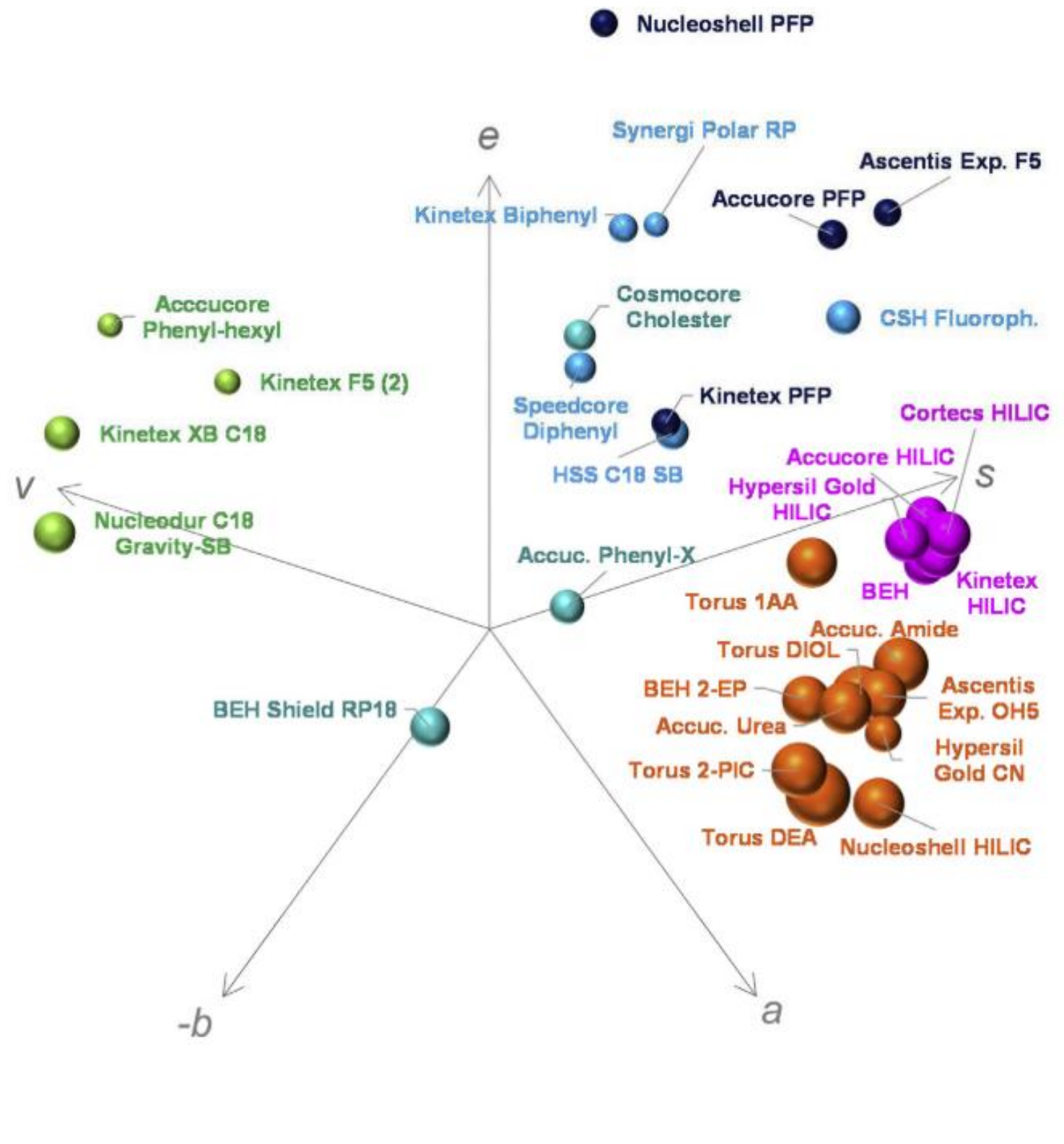


1 Figure 3: Schematic view of Infinity 1260 SFC system (Agilent Technologies) and its 2 hyphenation with mass spectrometry. ${ }^{7}$

3

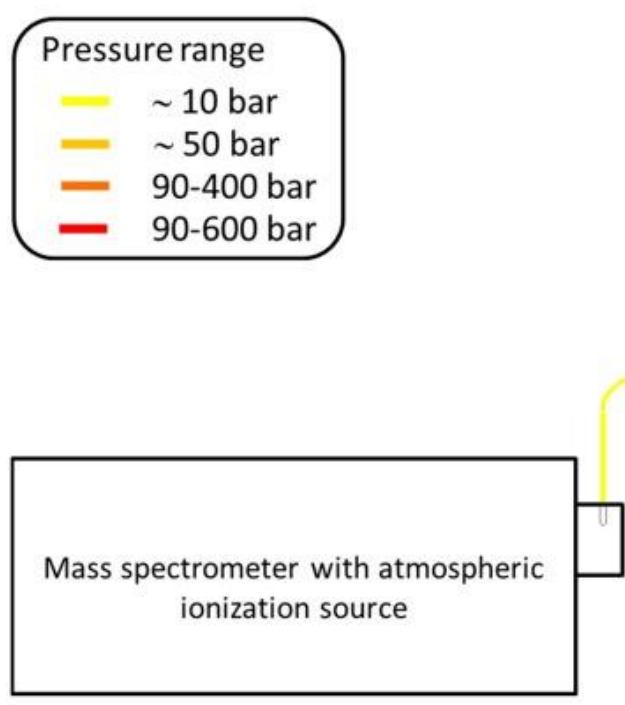

4 5 6

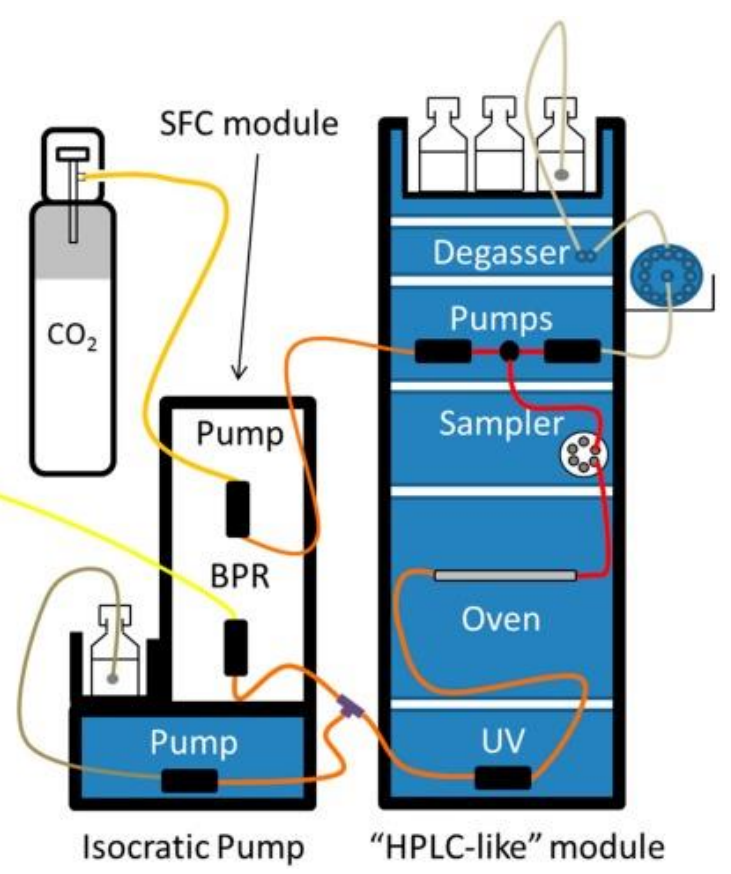


1 Figure 4: Schematic representation of various SFC-MS interfacing configurations. ${ }^{32}$ (a) 2 Chromatographic column is connected directly to MS through a pressure restrictor heated at 3 its end, (b) same as in (a) but here the restrictor is heated at the beginning, (c) Full flow from 4 the column is first passed through a UV detector, and then is mixed with an organic solvent 5 delivered by a fixed-pressure pump, before being expanded to MS through a restrictor, (d) 6 here flow from the column is passed through an automated back-pressure regulator (ABPR) 7 before the MS and the flow is mixed with a make-up pump flow, either before or after the 8 ABPR, (e) here a part of the outlet from the column is directed towards an MS whereas the 9 other part is taken to an ABPR passing through a UV detector, (f) in this configuration, flow 10 from the column is first passed through a UV detector, and then is mixed with an organic 11 solvent delivered by a make-up pump. A part of the mixed stream is then taken to the MS and 12 the other part to an ABPR.

(a)

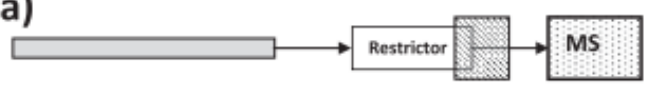

(b)

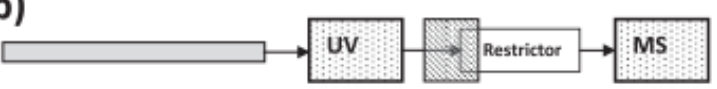

(c)

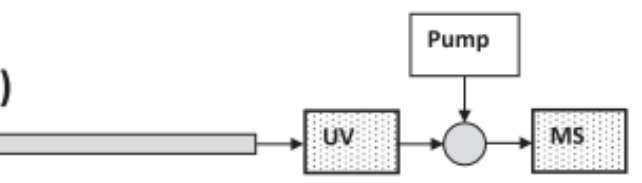

(d)

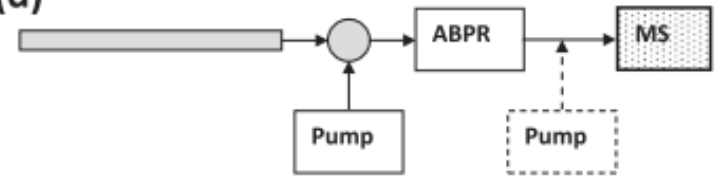

(e)

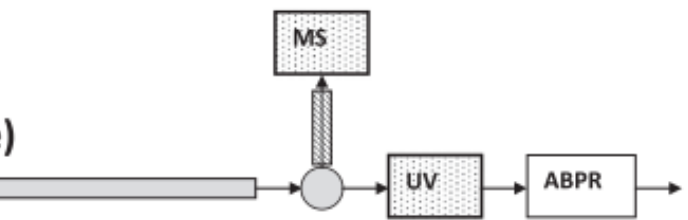

Full-flow

introduction

Split-flow

introduction

(f)

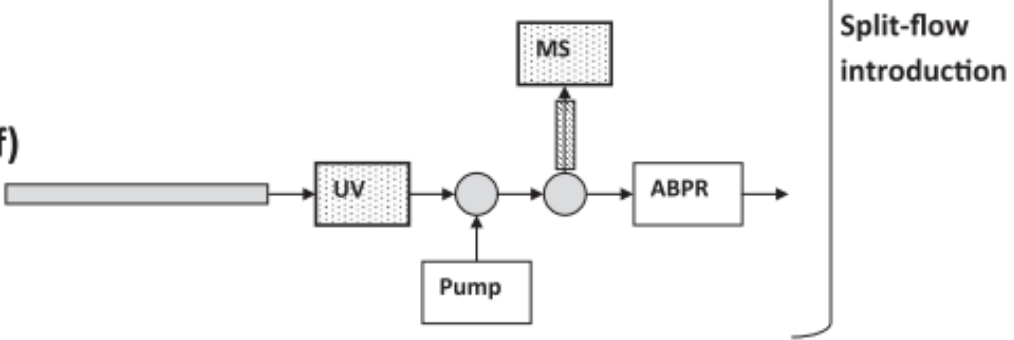


1 Figure 5: UHPSFC/ESI-MS extracted ion chromatogramms in positive (a) and negative (b) ion 2 mode of the major peaks of the main classes of lipid detected in the extract of Nannochloropsis 3 microalgae. UHPSFC conditions: Torus DEA column $(150 \times 2.1 \mathrm{~mm}, 1.7 \mu \mathrm{m}$, Waters $)$, the flow 4 rate $1 \mathrm{~mL} \cdot \mathrm{min}^{-1}$, the column temperature $60^{\circ} \mathrm{C}$, the ABPR pressure 130 bar and the gradient 5 of methanol-ethanol mixture $(1: 1, \mathrm{v} / \mathrm{v})$ containing $20 \mathrm{mM}$ of ammonium acetate as the 6 modifier: $0 \mathrm{~min}, 1 \%$; $1.5 \mathrm{~min}, 4 \%$; 2.5 to $5.5 \mathrm{~min}, 15 \%$; $7.5 \mathrm{~min}, 30 \%$; 8.5 to $15 \mathrm{~min}$; $45 \%$.
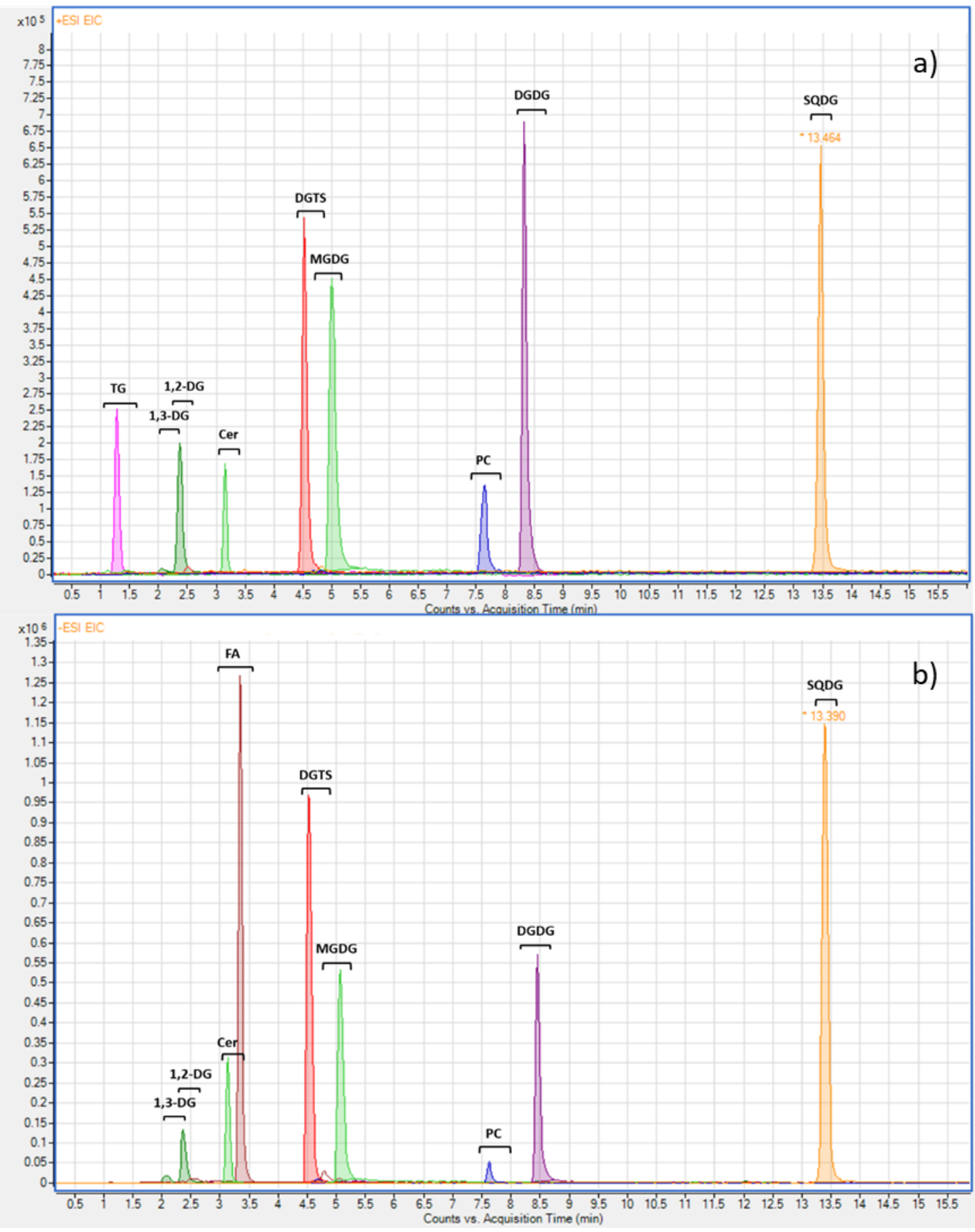
1 Figure 6: a) Extracted lon Chromatogram (EIC) of eight different triglycerides detected in the 2 extract of Nannochloropsis microalgae. b) Extracted Mass spectrum between 0.87 min and 31.79 min.

4
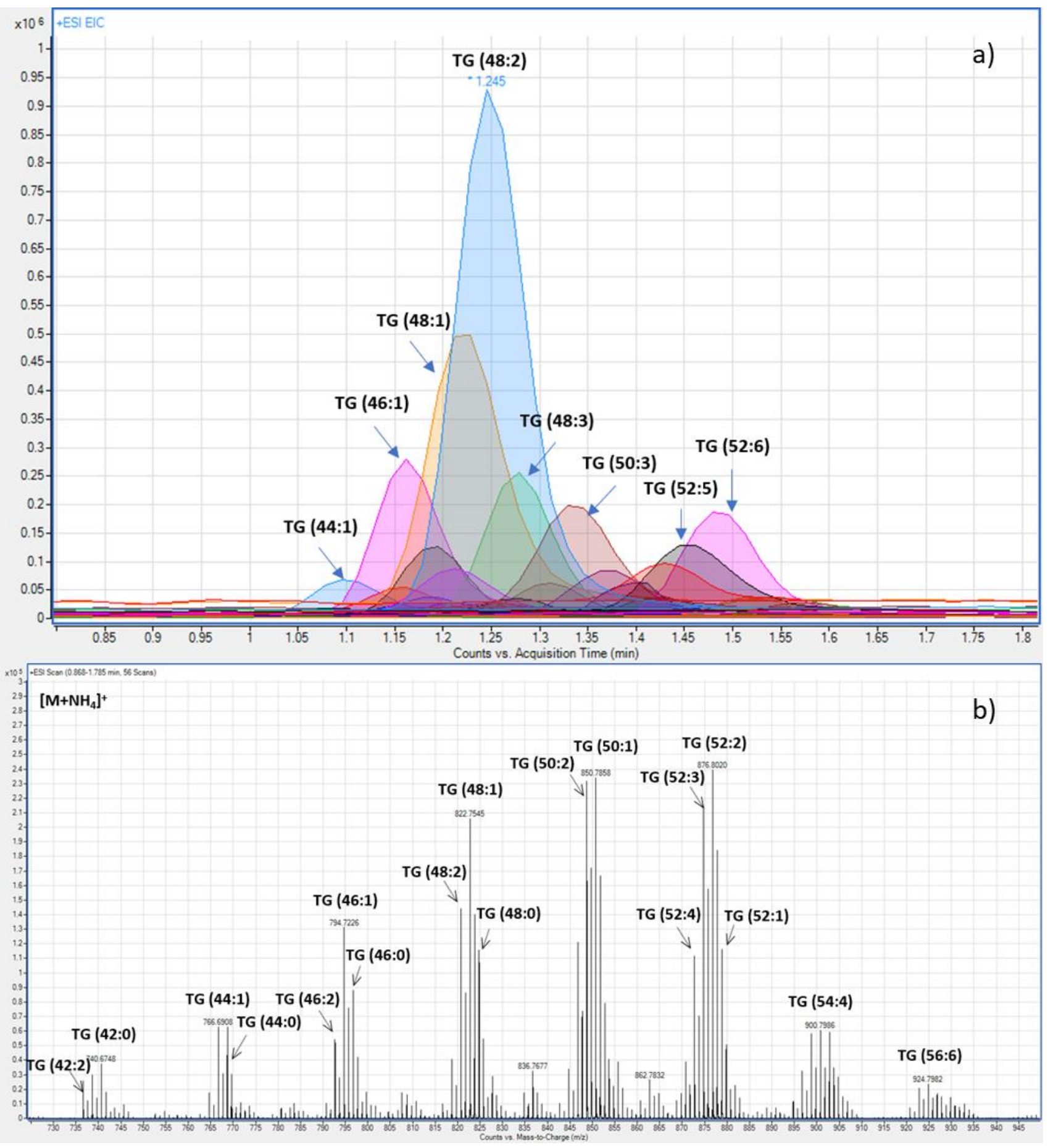
${ }^{1}$ A.A. Spector, M.A. Yorek. Membrane lipid composition and cellular function. J. Lipid Res. 1985, 26(9), 1015.

${ }^{2}$ D.J. Stephenson, L.A. Hoeferlin, C.E. Chalfant. Lipidomics in translational research and the clinical significance of lipid-based biomarkers. Transl. Res. 2017, 189, 13.

${ }^{3}$ F. Lamari, F. Mochel, F. Sedel, J.M. Saudubray. Disorders of phospholipids, sphingolipids and fatty acids biosynthesis: toward a new category of inherited metabolic diseases. J. Inherit. Metab. Dis. 2013, 36, 411.

${ }^{4}$ A.Z. Khan, A. Shahid, H. Cheng, S. Mahboob, K.A. Al-Ghanim, M. Bilal, F. Liang, M.Z. Nawaz. Omics Technologies for Microalgae-based Fuels and Chemicals: Challenges and Opportunities. Protein Pept. Lett. 2018, 25, 99.

${ }^{5}$ R.W. Gross. The evolution of lipidomics through space and time. Biochim. Biophys. Acta Mol. Cell Biol. Lipids. 2017, 1862(8), 731.

${ }^{6}$ X. Han. Lipidomics for precision medicine and metabolism: A personal view. Biochim. Biophys. Acta Mol. Cell. Biol. Lipids. 2017, 1862(8), 804.

${ }^{7}$ L. Laboureur, M. Ollero, D. Touboul. Lipidomics by Supercritical Fluid Chromatography. Int. J. Mol. Sci. 2015, 16(6), 13868.

${ }^{8}$ X. Zhang, X. Ding, J. Wang, B. Dean. Supercritical fluid chromatography-tandem mass spectrometry for high throughput bioanalysis of small molecules in drug discovery. J. Pharm. Biomed. Anal. 2019, 164, 62.

${ }^{9}$ E. Lesellier, C. West. The many faces of packed column supercritical fluid chromatography-a critical review. J. Chromatogr. A. 2015, 1382, 2.

${ }^{10}$ Ampère and Dulong, Rapport fait à l'Institut de France le 27 octobre 1823 sur un mémoire de M. Cagniard de La Tour, Am. Chim. Brochure 8 (série 2), XXI p12, WVII p410, 1823.

${ }^{11}$ T. Andrews. Philos. Trans. R. Soc. Lond., On the continuity of the gaseous and liquid states of matter. 1869, 159, 575 . 
12 L. Nováková, A. Grand-Guillaume Perrenoud, I. François, C. West, E. Lesellier, D. Guillarme. Modern analytical supercritical fluid chromatography using columns packed with sub-2 $\mu$ m particles: a tutorial. Anal. Chim. Acta. 2014, 824, 18.

${ }^{13}$ E. Klesper, A.H. Corwin, D.A. Turner. High Pressure Gas Chromatography above Critical Temperatures. J. org. Chem. 1962, 27, 700.

${ }^{14}$ P.A. Peaden, J.C. Fjeldsted, M.L. Lee, S.R. Springston, M. Novotny. Instrumental aspects of capillary supercritical fluid chromatography Anal. Chem. 1982, 54, 1090.

${ }^{15}$ M.A. Morrissey, H.M. Widmer. Ion-mobility spectrometry as a detection method for packedcolumn supercritical fluid chromatography J. Chromatogr. A. 1991, 552, 551.

${ }^{16}$ L.T. Taylor. Supercritical fluid chromatography for the 21 st century J. Supercritical Fluids. 2009, 47, 566.

17 J.B. Crowther, J.D. Henion. Supercritical fluid chromatography of polar drugs using smallparticle packed columns with mass spectrometric detection. Anal. Chem. 1985, 57, 2711.

18 J.D. Pinkston. Advantages and drawbacks of popular supercritical fluid chromatography / mass spectrometry interfacing approaches - a user's perspective. Eur. J. Mass Spectrom. 2005, 78, 7467.

${ }^{19}$ C. West, S. Khater, E. Lesellier. Characterization and use of hydrophilic interaction liquid chromatography type stationary phases in supercritical fluid chromatography. J. Chromatogr. A. 2012, 1250, 182.

20 T.A. Berger. Chromatography: supercritical fluid, theory of supercritical fluid chromatography. Editor lan D. Wilson, Encyclopedia of Separation Science. Academic Press. Oxford. 2007. p.1-9.

${ }^{21} \mathrm{E}$. Lesellier. Overview of the retention in subcritical fluid chromatography with varied polarity stationary phases. J. Sep. Sci. 2008, 31(8), 1238.

${ }^{22}$ C. West, E. Lemasson, S. Bertin, P. Hennig, E. Lesellier. An improved classification of stationary phases for ultra-high performance supercritical fluid chromatography. J. Chromatogr. A. 2016, 1440, 212. 
${ }^{23}$ C. West, E. Lesellier. A unified classification of stationary phases for packed column supercritical fluid chromatography. J. Chromatogr. A. 2008, 1191(1-2), 21.

${ }^{24}$ C. West, J. Melin, H. Ansouri, M. Mengue Metogo. Unravelling the effects of mobile phase additives in supercritical fluid chromatography. Part I: Polarity and acidity of the mobile phase. J. Chromatogr. A. 2017, 1492, 36.

${ }^{25}$ D. Wen., S.V. Olesik. Characterization of $\mathrm{pH}$ in liquid mixtures of methanol/ $/ \mathrm{H}_{2} \mathrm{O} / \mathrm{CO}_{2}$. Anal. Chem. 2000, 72, 475.

${ }^{26}$ Snyder L.R. Classification of the solvent properties of common liquids. J. Chromatogr. 1974, 92, 230.

27 M. Méjean, A. Brunelle, D. Touboul. Quantification of tocopherols and tocotrienols in soybean oil by supercritical-fluid chromatography coupled to high-resolution mass spectrometry. Anal. Bioanal. Chem. 2015, 407(17), 5133.

${ }^{28}$ L. Laboureur, N. Bonneau, P. Champy, A. Brunelle, D. Touboul. Structural Characterisation of Acetogenins from Annona muricata by Supercritical Fluid Chromatography Coupled to High-Resolution Tandem Mass Spectrometry. Phytochem. Anal. 2017, 28(6), 512.

${ }^{29}$ L. Laboureur, V. Guérineau, S. Auxilien, S. Yoshizawa, D. Touboul. Profiling of modified nucleosides from ribonucleic acid digestion by supercritical fluid chromatography coupled to high resolution mass spectrometry. J. Chromatogr. A. 2018, 1537, 118.

${ }^{30}$ C. Santerre, N. Vallet, D. Touboul. Fingerprints of flower absolutes using supercritical fluid chromatography hyphenated with high resolution mass spectrometry. J. Chromatogr. $B$ Analyt. Technol. Biomed. Life Sci. 2018, 1092, 1.

31 A. Grand-Guillaume Perrenoud, J.L. Veuthey, D. Guillarme. Coupling state-of-the-art supercritical fluid chromatography and mass spectrometry: From hyphenation interface optimization to high-sensitivity analysis of pharmaceutical compounds. J. Chromatogr. A, 2014, 1339, 174.

${ }^{32}$ A. Tarafder. Designs and methods for interfacing SFC with MS. J. Chromatogr. B, 2018, $1091,1$.

${ }^{33}$ J. Duval, C. Colas, V. Pecher, M. Poujol, J.F. Tranchant, E. Lesellier. Hyphenation of ultra high performance supercritical fluid chromatography with atmospheric pressure chemical 
ionisation high resolution mass spectrometry: Part 1 . Study of the coupling parameters for the analysis of natural non-polar compounds. J. Chromatogr. A. 2017, 1509, 132.

34 J. Duval, C. Colas, P. Bonnet, E. Lesellier. Hyphenation of ultra-high performance supercritical fluid chromatography with atmospheric pressure chemical ionisation high resolution mass spectrometry: Part 2. Study of chromatographic and mass spectrometry parameters for the analysis of natural non-polar compounds. J. Chromatogr. A. 2019, 1596, 199.

${ }^{35}$ S. Qu, Z. Du, Y. Zhang. Direct detection of free fatty acids in edible oils using supercritical fluid chromatography coupled with mass spectrometry. Food Chem. 2015, 170, 463.

${ }^{36}$ S.J. Kumari A Ubhayasekera, S.R. Acharya, J. Bergquist. A novel, fast and sensitive supercritical fluid chromatography-tandem mass spectrometry (SFC-MS/MS) method for analysis of arachidonic acid metabolites. Analyst 2018, 143(15), 3661.

37 J. Teubel, B. Wüst, C.G. Schipke, O. Peters, M.K. Parr. Methods in endogenous steroid profiling - A comparison of gas chromatography mass spectrometry (GC-MS) with supercritical fluid chromatography tandem mass spectrometry (SFC-MS/MS). J. Chromatogr. A. 2018, 1554, 101.

${ }^{38}$ T. Bamba, N. Shimonishi, A. Matsubara, K. Hirata, Y. Nakazawa, A. Kobayashi, E. Fukusaki. High throughput and exhaustive analysis of diverse lipids by using supercritical fluid chromatography-mass spectrometry for metabolomics. J. Biosci. Bioeng. 2008, 105, 460.

39 J.W. Lee, T. Yamamoto, T. Uchikata, A. Matsubara, E. Fukusaki, T. Bamba. Development of a polar lipid profiling method by supercritical fluid chromatography/mass spectrometry. $J$. Sep. Sci. 2011, 24, 3553.

40 T. Uchikata, A. Matsubara, E. Fukusaki, T. Bamba. High-throughput phospholipid profiling system based on supercritical fluid extraction-supercritical fluid chromatography/mass spectrometry for dried plasma spot analysis. J. Chromatogr. A. 2012, 1250, 69.

${ }^{41}$ H. Takeda, Y. Izumi, M. Takahashi, T. Paxton, S. Tamura, T. Koike, Y. Yu, N. Kato, K. Nagase, M. Shiomi, T. Bamba. Widely-targeted quantitative lipidomics method by supercritical fluid chromatography triple quadrupole mass spectrometry. J. Lipid Res. 2018, 59(7), 1283. 
${ }^{42}$ M. Lisa, M. Holcapek. High-Throughput and Comprehensive Lipidomic Analysis Using Ultrahigh-Performance Supercritical Fluid Chromatography-Mass Spectrometry. Anal. Chem. 2015, 87, 7187.

${ }^{43} \mathrm{~A}$. Dispas, et al. First inter-laboratory study of a Supercritical Fluid Chromatography method for the determination of pharmaceutical impurities. J. Pharm. Biomed. Anal. 2018, 161, 414.

${ }^{44}$ X. Ma, Y. Xia. Pinpointing double bonds in lipids by Paternò-Büchi reactions and mass spectrometry. Angew. Chem. Int. Ed. Engl. 2014, 53(10), 2592.

${ }^{45}$ F. Olivon, N. Elie, G. Grelier, F. Roussi, M. Litaudon, D. Touboul. MetGem Software for the Generation of Molecular Networks Based on the t-SNE Algorithm. Anal. Chem. 2018, 90(23), 13900. 